\title{
Implementación de las 10 estrategias por la seguridad del paciente en el Instituto Nacional de Neurología y Neurocirugía
}

\section{Implementation of the 10 strategies for patient safety in the National Institute of Neurology and Neurosurgery}

$\mathrm{L}$ a Organización Mundial de la Salud (OMS), a través de su dirección general, pone en marcha en octubre de 2004 la Alianza Mundial para la Seguridad del Paciente. Este organismo es un medio que propicia la colaboración internacional y la acción de los Estados Miembros, a través de la OMS y de los expertos, usuarios y grupos de profesionales en las Instituciones de Salud, como lo hace el Instituto Nacional de Neurología y Neurocirugía. El propósito es difundir las mejoras en materia de seguridad del paciente, tanto en la institución como en todo el mundo. En este orden de ideas, se puede decir que la seguridad del paciente es actualmente un problema de salud pública en todo el mundo; se calcula que 1 de cada 10 pacientes sufre algún tipo de daño durante su estancia en el hospital; por lo tanto, este problema es considerado como de gran importancia en todos los países que integran la OMS, así como aquellos en vías de desarrollo. El fenómeno se ha venido estudiando por el aumento en la probabilidad que tienen los pacientes de sufrir algún daño durante su ingreso al hospital.

Es por ello que se dan a conocer las 10 principales soluciones para que el profesional de enfermería brinde seguridad al paciente, las que a continuación se mencionan:

1. Identificación del paciente: meta 1. Utilizar cuando menos dos datos diferentes (nombre y registro); nunca el número de cama.

2. Comunicación clara y efectiva: meta 2. Se debe utilizar la terminología estandarizada, ser claro, conciso, específico y oportuno, además de cerciorarse de que se ha dado a entender (escucho, escribo, leo y confirmo); se debe repetir la orden y mencionar quién la recibe en voz alta.
3. Asegurar la precisión de la medicación: meta 3. El manejo de los cinco "correctos": paciente correcto, medicamento correcto, dosis correcta, vía correcta y rapidez correcta, así como mejorar la seguridad de los medicamentos para evitar errores a través de una estrategia de identificación; por ejemplo: Etiqueta roja: identifica electrolitos, glucosa al 50\%, insulina, heparina, enoxoparina, ciclofosfamidas y citotóxicos; etiqueta amarilla: inotrópicos; etiqueta azul: sedantes y relajantes; etiqueta verde: antibióticos.

4. Uso de protocolos y/o guías para diagnóstico: se deben seguir los protocolos y/o guías diagnósticas de acuerdo al paciente.

5. Cirugías y procedimientos correctos: meta 4. "Cirugía segura”: paciente correcto, cirugía, sitio quirúrgico correcto, momento correcto, procedimiento correcto, estudio de gabinete correcto (tomografía, imagen de resonancia magnética, punción lumbar, terapia electroconvulsivante).

6. Prevención de infecciones nosocomiales: meta 5. El lavado de las manos para todo el personal del Instituto Nacional de Neurología y Neurocirugía (INNN) al llevar a cabo las 11 recomendaciones en un tiempo de 40-60 segundos, así como la aplicación de los "cinco momentos": antes del contacto con el paciente, antes de realizar una tarea aséptica, después del riesgo de exposición a líquidos corporales, después del contacto con el paciente, así como después del contacto con el entorno del paciente.

7. Prevención de caídas de los pacientes: meta 6. Identificar en los pacientes (factores intrínsecos y extrínsecos) situaciones de alto riesgo. La estrategia es aplicar la escala de Downton y llevar la escala 0 (no), 1 (sí)

Correspondencia: Ma. Guadalupe Nava Galán. Insurgentes Sur 3877, Colonia La Fama, Delegación Tlalpan, C.P. 14269

E-mail: magpengalan@hotmail.com

Este artículo puede ser consultado en versión completa en http://www.medigraphic.com/enfermerianeurologica 
valorando: medicación, déficit sensorial, estado mental y deambulación. Otra estrategia: "dejar los barandales de la cama arriba siempre e informar al paciente y sus familiares sobre las medidas preventivas."

8. Factores humanos: si no se encuentra al $100 \%$ de sus capacidades (por cansancio, prisa o algún otro problema) extérnelo y pida ayuda. Si tiene duda, pregunte al especialista indicado.

9. Clima de seguridad: se debe manifestar ejemplo de conciencia y cuidado frente a las acciones con las medidas de seguridad del paciente.

10. Haga corresponsable al paciente-familiar: esto facilita que expresen sus dudas.

Nota: se debe verificar que el paciente haya entendido su padecimiento así como su tratamiento y rectifique todos los tratamientos a los que está siendo sometido, inclusive los alternativos. Incluya esta información en el enlace a otros servicios.

En los últimos meses, el Centro Colaborador de la OMS ha reunido a más de 50 destacados líderes y expertos de todo el mundo en ese campo para identificar y adaptar las nueve soluciones a diferentes necesidades. ${ }^{1}$

Estas soluciones ofrecen, a través de la OMS, un nuevo e importante recurso para ayudar a los hospitales e instituciones a evitar muertes y lesiones prevenibles; así lo señaló Dennis S. O'Leary, M.D., Presidente de The Joint Commission: "Todos los países afrontan hoy tanto la oportunidad como el reto de traducir esas soluciones en acciones concretas que efectivamente salven vidas." ${ }^{2}$

Ma. Guadalupe Nava Galán

1 Agnes Leotsakos. OMS, Alianza Mundial para la Seguridad del Paciente. Ginebra, Suiza:Tel: +41 22791 2567;E-mail: HYPERLINK “mailto:leotsakosa@ who.int” leotsakosa@who.int

2 Charlene D. Hill. The Joint Commission. En Washington, E.U., Tel: +1630 792 5175, E-mail: HYPERLINK "mailto:chill@jointcommission.org" chill@ jointcommission.org 